\title{
Outcome at 2-year of treatment in first-episode psychosis patients who were enrolled in a specialized early intervention program
}

\author{
Anna Meneghelli, Simona Barbera, Maria Meliante, Emiliano Monzani, Antonio Preti, \\ Angelo Cocchi, Mauro Percudani* \\ Programma2000 - Center for Early Detection and Intervention in Psychosis, Department of Mental Health, ASST Niguarda Hospital, Milan, Italy
}

\section{A R T I C L E I N F O}

\section{Keywords:}

Psychosis

Schizophrenia

Growth mixed model

Heterogeneity

Early intervention

\begin{abstract}
A B S T R A C T
Treatment in early intervention services (EIS) seems superior to treatment as usual on several outcomes, but the extent of heterogeneity in response is unclear. In this study, treatment response trajectories up to 2 years in firstepisode psychosis (FEP) patients enrolled in an Italian early intervention service (EIS) have been quantified. The 24-item Brief Psychiatric Rating Scale (BPRS) was used to quantify treatment response up to 2 years in 129 participants. Conditional growth modeling and latent class growth analysis were used to test changes over time in the BPRS and separation into independent classes over time. Group differences were tested on socio-demographic and clinical variables known to be related to outcome in psychosis. Scores on the BPRS showed a statistically significant decrease in overall scores across all tested models. Four trajectories were identified across 2 years. Most patients showed a progressive decrease in the BPRS scores; a scant fraction showed a more stepped decrease from very high levels of psychopathology. No potential predictor was statistically related to the time course of BPRS scores. Most patients that undergo treatment within an EIS are characterized by amelioration, but patients that have higher baseline scores of psychopathology require more intensive treatment.
\end{abstract}

\section{Introduction}

Schizophrenia spectrum disorders import a high burden of care, reduced quality of life, enhanced death rates, and elevated personal, family and societal costs (Awad and Voruganti, 2008; Laursen et al., 2014; Cloutier et al., 2016; Jin and Mosweu, 2017; Watson et al., 2018). There is evidence that a combination of drug and psychosocial treatment may improve the long-term outcome of patients with schizophrenia spectrum disorders (Harding et al., 1987; Volavka and Vevera, 2018). There is also some evidence that early course patterns within the first 2 years of treatment are the strongest predictor of medium- (15 years) and long-term (25 years) outcome (Harrison et al., 2001; Lally et al., 2017). In particular, early treatment response was related to long-term outcome (Emsley et al., 2008), and, in general, the duration of untreated psychosis (DUP), i.e. the time from manifestation of the first psychotic symptom to initiation of adequate treatment, was a predictor of outcome, with longer DUP related to poor general symptomatic outcome, poor social functioning and lesser likelihood of remission (Penttilä et al., 2014). However, the links between DUP and long-term outcome might be a reflection of the better prognosis of cases with acute onset when compared to cases with insidious onset
(Volavka and Vevera, 2018). In first-episode psychosis (FEP), predictors of relapse following discontinuation of treatment after remission from the episode were male sex, prior psychiatric admission, and premorbid adjustment and functioning (Bowtell et al., 2018). Age of onset has a small but statistically significant impact on the outcome of patients diagnosed with schizophrenia, with younger age of onset being related to more hospitalization and poorer global outcome (Immonen et al., 2017). However, age of onset might be confounded by gender differences, with men having younger age of onset than women (Cascio et al., 2012), and more likely than women to suffer from comorbidities that impact on outcome (Riecher-Rössler et al., 2018). Men, for example, are more likely than women to develop alcohol and substance use disorders (SUDs), which occur between $20 \%$ and $65 \%$ of samples depending on the setting and the type of SUD, with SUDs consistently related to poorer symptomatic outcome and greater chance of hospital admission as well as greater risk of violence, victimization and suicide (Kerfoot et al., 2011; Bennett et al., 2017). Family history of psychiatric disorders is a known risk factor for schizophrenia, however it is weakly related to global outcome (Käkelä et al., 2017). Nevertheless, when the investigation is restricted to a family history of psychosis, a relatively small but statistically significant association with the long-term

\footnotetext{
* Corresponding author at: Chair of the Dipartimento Salute Mentale e delle Dipendenze, Piazza Ospedale Maggiore, 3 20162, Milano, Italy.

E-mail addresses: apreti@tin.it (A. Preti), mauro.percudani@ospedaleniguarda.it (M. Percudani).
} 
occupational and global outcome is found in patients with schizophrenia (Käkelä et al., 2014). Besides age, sex, family history of psychosis, DUP, premorbid functioning, and SUDs, dropout of treatment was related to outcome in patients diagnosed with schizophreniaspectrum disorders. Dropout was consistently associated with a reduced chance of improvement, and the severity of the symptoms before the last visit was related to a greater chance of dropout (Rabinowitz and Davidov, 2008).

Since the 19th century, clinicians agreed that treatment would be the most effective at the early stage of the mental illness. Among others, influential authors, such as Winslow (1860), who was specialized in forensic psychiatry (Winslow, 1858), and Jean-Étienne Dominique Esquirol (1845), one of the fathers of modern psychiatry (Charland, 2015), held that mental disorders are preceded by a period of incubation during which early symptoms, including changes of habits, are prone to be overlooked. These authors suggested treating these early symptoms as soon as possible. However, during the 19th century patients were rarely treated in a timely fashion, also because of the lack of effective treatment, as summarized in a recent review on the topic (Chau et al., 2018). In modern times, converging evidence suggests that early intervention in psychosis may have a favorable impact on remission of positive and negative symptoms and functional recovery (McGorry, 2015; Santesteban-Echarri et al., 2017). Across 10 randomized clinical trials involving 2176 patients with FEP, treatment in early intervention services was superior to treatment as usual in total symptom severity (standardized mean difference [SMD], $-0.32 ; 95 \%$ CI: -0.47 to -0.17 ), positive symptom severity (SMD: $-0.22 ;-0.32$ to -0.11 ), negative symptom severity (SMD: -0.28 ; -0.42 to -0.14 ), and in school or work functioning (risk ratio: 1.13; 95\% CI: 1.03-1.24) (Correll et al., 2018).

Most studies insofar had investigated the outcome of the first episode of psychosis assuming a linear trajectory from baseline to the considered endpoints. However, there is increasing evidence that improvement in patients with FEP is heterogeneous, with patients with better premorbid functioning and higher cognitive scores showing the most improvement (Levine et al., 2010; Levine and Rabinowitz, 2010), and those with most severe negative symptoms at inception having a reduced chance of improvement (Horton et al., 2015). Overall, those who continue to improve are more likely to stay in treatment compared to those who only experience temporary relief, who are more likely to drop out of treatment (Kong and Chen, 2016). Differences in the trajectories of improvement in FEP patients may be related to predictors that are amenable to intervention, thus their investigation may offer clues to improve the course of these disorders.

\subsection{Aims}

This study was set out to investigate the outcome of FEP patients who were treated for 2 years in an early intervention service. We aimed at a) establishing the impact of known predictors of outcome in schizophrenia spectrum disorders; and, b) estimating empirically-derived trajectories in change over time of the severity of symptoms to quantify the extent of heterogeneity in treatment response and to identify subgroup characteristics in treatment response. Mixed models of growth curves and latent class growth analysis were applied to pursue these aims of the study.

\section{Methods}

The study was carried out in the Programma2000 service, the early intervention service operating under the Health Authority of the ASST Niguarda Hospital of Milan (Cocchi et al., 2008). Data were collected during the routine assessment of the patients participating in the Programma2000 and, more specifically, of those enrolled from June 1999 to December 2014. The study protocol complies with the guidelines of the 1995 Declaration of Helsinki, as revised in Tokyo in 2004, and further revised in Fortaleza, Brazil, in 2013 (World Medical Association, 2013). All included patients gave their informed consent.

\subsection{Participants}

Programma2000 is a multi-modal, community-based program on early intervention in psychosis settled in Italy, Milan, since 1999. Programma2000 operates as an assessment and treatment hub for several referral agencies, ranging from institutionally mediated pathways (e.g. primary care, district $\mathrm{MH}$, school counseling, emergency rooms) to spontaneous help-seeking individuals (e.g. self-referrals or family referrals in response to awareness campaigns). The served catchment area includes approximately 200,000 inhabitants. Criteria for referral and preliminary evaluation are: age between 17 years and 30 years and help-seeking for early or impending psychosis.

Participants who were included in this study were patients diagnosed with FEP, operatively defined as: a diagnosis of schizophrenia or related syndromes (such as F20-29 in ICD-10) according to the ICD-10 (World Health Organization, 1992), with duration of untreated psychosis (DUP) less than 24 months, which is considered the limit to start an effective early intervention protocol of care (Birchwood, 2000). The majority of this group includes subjects referred to Programma2000 immediately after a first contact with any public mental health service of the catchment area and contextually diagnosed as suffering from non-affective psychosis prior to admission.

Exclusion criteria were: comorbid medical or neurological disorders; affective psychosis (bipolar disorder, or unipolar disorder with psychotic features); substance use disorders. Subjects with some recreational substance use not associated with substance use disorder were deemed eligible for treatment.

The enrolled patients received a three-years comprehensive, tailored and flexible intervention package. Prescribed tailored interventions included individual psycho-educational and motivational sessions, cognitive-behavioral psychotherapy, individual family psycho-education and support, therapeutic group activities (e.g., anxiety management, assertive and problem-solving training, etc.), various social group activities (e.g., music, multimedia, empowerment, computer training sessions, language classes, etc.), and supportive interventions on employment, school, compliance with medication, and planning of recreational activities (Cocchi et al., 2008; Meneghelli et al., 2010).

\subsection{Measures}

The following measures and indicators were used in this study: gender (boy or girl); age at first contact (years old); the 24-item Brief Psychiatric Rating Scale (BPRS; Overall and Gorham, 1962; Roncone et al., 1999); the DUP; past admissions to hospital for psychiatric reasons; recreational substance use not associated with substance use disorder; family history of psychiatric disorders; dropout of treatment after the first two years for any reason; premorbid functioning.

Gender and age at first contact were derived from a socio-demographic form that is regularly filled in at first contact. The BPRS was used to assess general psychopathology, and it was the main measure of outcome. The BRPS is a 24-item measure of general psychopathology in a Likert format, with scores ranging from 1 (absent) to 7 (extremely severe). The range of possible BPRS total scores is 24 to 168, with higher scores indicating higher levels of psychopathology. The BPRS was regularly administered to the patients at inception and then every 6 months, to assess levels of psychopathology and its change over time. BPRS was assessed by raters with a minimum of two years experience in rating patients diagnosed with psychosis. All raters were individually trained to apply the scales and the interviews that are part of the assessment package of the Programma2000. Inter-rater agreement among the clinical staff was regularly checked to assure good-to-acceptable concordance on the scales. Median intra-class correlation coefficients 
(ICC) for BPRS, calculated with a 2-way mixed-effects model, were 0.70 or above when performed on a small sample of patients $(n=25)$ during training. As in past studies (Ventura et al., 1993; Roncone et al., 1999), ICC were better for items related to patients' self-report $(>0.80)$ than for items based on raters' observation of the patients' behavior (around 0.60 ). Current guidelines suggest that ICC values between 0.5 and 0.75 , between 0.75 and 0.9 , and greater than 0.90 are indicative of moderate, good, and excellent reliability, respectively (Koo and Li, 2016).

Improvement on the BPRS across time was measured as the difference between the score at baseline (minus the minimum score of 24 , as in Leucht, 2014) and the score at the end of the 2 years treatment (again, minus the minimum score of 24).

The DUP was measured (in days) as the time elapsed from the onset of key symptoms (hallucinations, delusions or bizarre behavior) to the beginning of treatment (pharmacotherapy or psychotherapy) prescribed by a psychiatrist, on the basis of an interview that was administered to the patients at their fist contact with the Programma2000, the Early Recognition Inventory Retrospective Assessment of Symptoms checklist (ERIraos-CL), a 17-item screening checklist intended to select persons needing a more in-depth assessment. The ERIraos-CL has 17 items designed to assist the exploration of individual proneness to schizophrenia, including items about changes in perception and thought interference and two items about paranoid ideation and hallucinations, which are more clearly indicative of psychosis (Häfner et al., 1992; Raballo et al., 2014). Data on past admissions to hospital for psychiatric reasons other than psychosis, on recreational substance use and substance use disorders, on family history of psychiatric disorders, and on premorbid functioning were based on a detailed interview with the patient and a key informant (a close relative, usually a parent). Past admissions to hospital for psychiatric reasons other than psychosis was assessed as yes/no and included any past admission to a psychiatric service as reported by the patients and confirmed by inspection of the records. Recreational substance use and substance use disorders were investigated by asking whether the patient had received any diagnosis of substance use disorder in the last 24 months, or habitually consumed a drug from a list including cannabis, cocaine, heroin/opiates, amphetamine and its derivatives, hallucinogens and a residual class of "others". Recreational substance use was coded as yes/no whether the patient had a history of recreational substance use or not, irrespectively from the used drug. Family history of psychiatric disorders was investigated by asking if someone among close relatives (parents, grandparents, uncles and aunts, siblings, and cousins) had ever received a diagnosis of a mental disorder from a list including major mental disorders, or had ever been admitted to a psychiatric services, or had ever received the prescription of antipsychotics, mood stabilizers or antidepressants as listed with their generic and commercial names. A family history of psychiatric disorders was coded as yes/no irrespectively from the number of affected relatives. Premorbid functioning was coded as yes/no according to whether the patients have had a decline in their functioning at school/ work or with their social relationship with peers in the past two years before contact with the center. Information on dropout was derived from the clinical charts and it was coded as yes/no irrespectively from the reasons for dropout.

\subsection{Statistics}

Exploratory data analysis and descriptive statistics were carried out using the Statistical Package for Social Sciences (SPSS) version 20. Additional analyses were carried out in R (R Core Team, 2018) using dedicated packages. All tests were two-tailed, with alpha set at $p<0.05$. Means with standard deviations were reported for continuous variables. Counts and percentages were reported for categorical variables. Continuous variables were tested with Student's $t$-test or ANOVA. Categorical analyses were carried out with the chi-square, along with Yates correction, whenever necessary.
A conditional growth model was used to analyze changes over time in the variable of interest (BPRS total score). The Restricted Maximum Likelihood estimation (REML), a linear mixed-effects model, was adopted using the "nlme" package running in R (Pinheiro et al., 2016). Change over time was tested in the variable of interest, as was the differential impact of gender (boys versus girls), age (less than 20 years old vs 21 years old or older), DUP (less than 90 days vs more than 3 months); past admissions to hospital for psychiatric reasons other than psychosis (yes vs no); recreational substance use (yes vs no); family history of psychiatric disorders (yes vs no); premorbid functioning (decline vs no decline); dropout of treatment after the first two years for any reason (yes vs no).

The conditional (pseudo) $\mathrm{R}^{2}$, describing the proportion of variance explained by both fixed (time and group membership) and random factors (participants), was used as a rough measure of the model fit. The conditional (pseudo) $\mathrm{R}^{2}$ was calculated according to Nakagawa et al. (2017). The analyses were performed with the "MuMIn" package running in R (Barton, 2018).

Latent class growth analysis (LCGA) was applied to identify separate trajectories of subgroups of patients across time. LCGA identifies distinct subgroups of individuals following a distinct pattern of change over time on the variable of interest (Andruff et al., 2009). According to the conventional growth model, intercept and slope of longitudinal data across time are expected to vary across individuals and random effects capture this heterogeneity. However, this approach assumes that all individuals are drawn from a single population with common parameters. In LCGA, different groups of individual growth trajectories are expected to vary around different means (with the same or different forms), thus separate growth models are estimated for each latent class, each with its unique estimates of variances and covariate influences (Jung and Wickrama, 2008). In the model, the dependent variable (total score on the BPRS) was explained according to a quadratic function of time at the population level (fixed effects), and a linear function of time at the individual level. We expected that scores on the BPRS could decrease smoothly across time, or that scores could increase at the beginning and then decrease or, else, that scores could decrease at the beginning and then increase thereafter. One to six classes were tested. The package "lcmm" running in R was used to apply LCGA to the data (Proust-Lima et al., 2017). The best model was expected to minimize the values of the Akaike information criterion (AIC; Akaike, 1987), of the Bayesian information criterion (BIC; Schwarz, 1978), and of the sample-size adjusted BIC (SABIC, Sclove, 1987), and to maximize entropy, which was used to assess accuracy of participants' classification (0 to 1 ), with higher values indicating better classification. Entropy values greater than 0.80 indicate a good separation of the identified groups (Ramaswamy et al., 1993). Participants were assigned to the latent class they had the highest probability of belonging to (average probabilities per class $\geq 90 \%$ at a minimum was accepted).

Logistic regression was used to assess the association between class membership and potential predictors of class membership. The same variables of interest that were tested in the conditional growth model were applied to the results of the LCGA. Differences between classes were expressed with odds ratio (95\% confidence interval [CI]). Variance explained by the model ( 0 to $100 \%$ ) was assessed with the pseudo- $\mathrm{R}^{2}$ McFadden measure, with higher values being a reflection of better fit of the model (Long, 1997).

\section{Results}

Overall, there were 129 patients diagnosed with non-affective firstepisode psychosis who completed the first two years of treatment at the Programma2000 during the interval of time that was considered in this study (1999 to 2016). Table 1 summarizes the main characteristics of the sample. Most patients were boys, and the mean age in the sample was 22 years old, with boys younger than girls $(21 \pm 3$ versus $23 \pm 4$; 
Table 1

General characteristics of the sample ( $n=129$ ).

All data are reported as mean (standard deviation); range, or counts (percentage).

\begin{tabular}{|c|c|}
\hline \multicolumn{2}{|l|}{ Gender } \\
\hline Boys & $105(81 \%)$ \\
\hline Girls & $24(19 \%)$ \\
\hline Age (years old) & 22 (4); range: $16-31$ \\
\hline 16 to 20 years old & $53(41 \%)$ \\
\hline 21 years old or older & $76(59 \%)$ \\
\hline DUP (days) & 152 (205); range: $0-730$ \\
\hline Less than 90 days & $66(51 \%)$ \\
\hline 3 months or more & $45(35 \%)$ \\
\hline The DUP could not be determined & $18(14 \%)$ \\
\hline \multicolumn{2}{|l|}{ Past admissions for psychiatic reasons } \\
\hline Yes & $69(53 \%)$ \\
\hline No & $60(47 \%)$ \\
\hline \multicolumn{2}{|l|}{ History of recreational substance use } \\
\hline Yes & $30(23 \%)$ \\
\hline No & $90(70 \%)$ \\
\hline Not enough information & $9(7 \%)$ \\
\hline \multicolumn{2}{|l|}{ Family history of psychiatric disorders } \\
\hline Yes & $76(59 \%)$ \\
\hline No & $40(41 \%)$ \\
\hline Not enough information & $13(10 \%)$ \\
\hline \multicolumn{2}{|l|}{ Decline in premorbid functioning } \\
\hline Yes & $95(74 \%)$ \\
\hline No & $23(18 \%)$ \\
\hline Not enough information & $11(8 \%)$ \\
\hline \multicolumn{2}{|l|}{ Dropout of treatment after 2 years } \\
\hline Yes & $38(29 \%)$ \\
\hline No & $91(71 \%)$ \\
\hline \multicolumn{2}{|l|}{ BPRS } \\
\hline Baseline & 50 (17); range: 24 - 105 \\
\hline At 6 months & 39 (14); range: 21 - 97 \\
\hline At 12 months & 38 (15); range: $24-103$ \\
\hline At 18 months & 35 (9); range: $24-66$ \\
\hline At 24 monts & 34 (9); range: $24-77$ \\
\hline
\end{tabular}

$t=2.24, p=0.026$ ). About half of the sample had a DUP less than 90 days, suggesting an acute onset of the condition.

A past admission for psychiatric reasons other than psychosis was reported in $53 \%$ of the sample. Many patients reported a family history of psychiatric disorders (59\%). Among those with a family history of psychiatric disorders, 24 reported that the diagnosis in the relative was a non-affective psychosis (32\%), and 29 reported that the diagnosis in the relative was an affective disorder (38\%), either major depressive disorder or bipolar disorder. Recreational substance use was observed in about a quarter of the sample (23\%). Up to two-thirds of the participants showed evidence of a decline in premorbid functioning. Over time, the decrease in the BPRS score was on average $61 \%$, suggesting robust improvement in psychopathology.

\subsection{Results of the conditional growth model}

Scores on the BPRS decreased over time, with a statistically significant decrease of overall scores on the BPRS across all tested models (Table 2).

The decrease in BPRS scores was on average of 3 points every six months. Age, gender and DUP did not influence the time course of the decrease in BPRS scores. Those with past admissions for psychiatric reasons other than psychosis had a slower decline in BPRS scores compared to those without past admissions for psychiatric reasons. Patients who reported a family history of psychiatric disorders had a better course than those who did not. A history of recreational substance use and the occurrence of decline in premorbid functioning before the episode both were related to a lower improvement on the BPRS but the results were not statistically significant. Overall, the models had a good fit, with Conditional $R^{2}$ near or above $50 \%$. Most of the variance was explained by the change over time of the scores on the BPRS and the effect of the predictors was minimal.

\subsection{Results of the latent class growth analysis}

The indicators of fit decreased from the 1-class model to the 6-class model, however, the 4-class model had the best entropy, suggesting the best separation of the classes. The probability of assignment to their own class was above $90 \%$ in $86 \%$ of cases, which is the best performance among the models. Therefore the 4-class model was selected as the best description of the data in the sample (Table 3 ).

In the 4-class model, one hundred and twelve participants were assigned to class 1 (87\%), eight (6\%) were assigned to class 2, five (4\%) were assigned to class 3 , and four (3\%) were assigned to class 4 (Fig. 1).

The majority of the patients showed a progressive decrease in the BPRS scores; a scant fraction showed a more stepped decrease from very high levels of psychopathology (class 2), or had a small improvement at the first 6 months of treatment, followed by a worsening at 12 months and then a new decrease in BPRS scores (class 3). Finally, a residual group showed a sharp decrease in the first 6 months of treatment followed at 18 months by a worsening of their status (class 4).

No potential predictor was statistically related to the time course of BPRS scores as displayed across the four latent classes that were extracted by the best LCGA model, essentially because of the small sample size of three classes (Table 4).

\section{Discussion}

Most patients that undergo treatment within an early intervention service are characterized by amelioration and ongoing changes. This result is congruent with the amelioration that was observed in patients with recent-onset psychosis after the start of antipsychotic treatment (Levine et al., 2010; Levine and Rabinowitz, 2010). Patients that have higher baseline scores of psychopathology have a more stepped decrease of BPRS scores, probably requiring more intensive treatment. Overall, there was a trend for those with past admissions for psychiatric reasons other than psychosis, those with a history of recreational substance use, and those who reported the occurrence of decline in premorbid functioning to show a slower decrease in BPRS scores. These patients might benefit from more intensive or more focused treatment to overcome their difficulties. Interestingly, those who reported a family history of psychiatric disorders had a better course than those who did not. This might depend on the family with experience of psychopathology being more sensitive to the impact of mental disorders, thus being more involved in the treatment of their kin when they have a psychotic breakdown. This is a topic deserving of further investigation.

Overall, the improvement in the levels of psychopathology as measured by the BPRS was largely explained by the change over time of the BPRS scores, with minimal or null effect of the potential predictors. At least within the first 2 years of treatment, most predictors of the long-term course of schizophrenia-spectrum psychosis have no impact on the effects of treatment, or at least they have no impact on the patients that are undergoing treatment within an early intervention service. Since the study didn't have a control group of patients receiving treatment as usual, we cannot firmly state that the treatment within an early intervention service removes most of the impact of the predictors of long-term outcome in schizophrenia.

The Programma2000 is imbricated within the Lombardy mental health system of care. Lombardy is the largest and the most affluent region in Italy and has adopted an organizational model for the mental health care centered on multi-disciplinary teams, expected to be able to provide the full range of psychiatric care (Lora et al., 2012). In the last decade, a significant number of projects have been developed for early detection and interventions for severe mental disorders (Parabiaghi et al., 2019), and within these projects, Programma2000 invested since the beginning into the improvement of patients' 
Table 2

Results of the conditional growth models.

\begin{tabular}{|c|c|c|c|c|c|c|c|}
\hline \multirow[t]{2}{*}{ Variables in the model } & \multicolumn{7}{|c|}{ Statistics } \\
\hline & Beta & s.e. & $\mathrm{df}$ & $\mathrm{t}$ & $\mathrm{p}$ & Log likelihood (LL) & Conditional $\mathrm{R}^{2}$ \\
\hline Time & -3.9 & 0.9 & 514 & -4.4 & 0.0001 & $\mathrm{LL}=-2540.7, p=0.020$ & $44.3 \%$ \\
\hline Gender & -0.7 & 4.3 & 127 & -0.1 & 0.87 & & \\
\hline Time $\mathrm{x}$ Gender & 0.4 & 1.0 & 514 & 0.4 & 0.64 & & \\
\hline Time & -3.4 & 0.4 & 514 & -7.1 & 0.0001 & $\mathrm{LL}=-2520.8, p=0.012$ & $49.6 \%$ \\
\hline Age & 5.1 & 3.3 & 127 & 1.5 & 0.12 & & \\
\hline Time $\mathrm{x}$ Age & -0.9 & 0.7 & 514 & -1.3 & 0.19 & & \\
\hline Time & -3.7 & 0.5 & 442 & -7.4 & 0.0001 & $\mathrm{LL}=-2176.3, p=0.007$ & $47.9 \%$ \\
\hline DUP & 5.5 & 3.5 & 109 & 1.6 & 0.11 & & \\
\hline Time $\mathrm{x}$ DUP & -0.9 & 0.8 & 442 & -1.1 & 0.25 & & \\
\hline Time & -2.8 & 0.5 & 514 & -5.0 & 0.0001 & $\mathrm{LL}=-2520.7, p=0.0004$ & $50.3 \%$ \\
\hline Past admissions & 4.3 & 3.4 & 127 & 1.2 & 0.20 & & \\
\hline Time $\mathrm{x}$ Past admissions & -1.6 & 0.7 & 514 & -2.2 & 0.026 & & \\
\hline Time & -3.9 & 0.4 & 478 & -9.5 & 0.0001 & $\mathrm{LL}=-2322.3, p=0.024$ & $52.0 \%$ \\
\hline \multirow[t]{2}{*}{ Recreational substance use Time x Substance use } & 1.2 & 3.7 & 118 & 0.3 & 0.75 & & \\
\hline & 0.1 & 0.8 & 478 & 0.1 & 0.08 & & \\
\hline Time & -2.6 & 0.6 & 462 & -3.9 & 0.0001 & $\mathrm{LL}=-2260.9, p=0.0001$ & $49.8 \%$ \\
\hline Family history & 6.1 & 3.6 & 114 & 1.7 & 0.095 & & \\
\hline Time $\mathrm{x}$ Family history & -1.9 & 0.8 & 462 & -2.4 & 0.014 & & \\
\hline Time & -2.5 & 0.8 & 470 & -3.1 & 0.0017 & $\mathrm{LL}=-2260.9, p=0.0001$ & $49.9 \%$ \\
\hline Prebordid functioning & 9.7 & 4.1 & 116 & 2.3 & 0.019 & & \\
\hline Time $\mathrm{x}$ preborbid functioning & -1.6 & 0.9 & 470 & -1.8 & 0.070 & & \\
\hline Time & -3.8 & 0.4 & 514 & -8.4 & 0.0001 & $\mathrm{LL}=-2293.1, p=0.0010$ & $49.9 \%$ \\
\hline Dropout & 2.1 & 3.7 & 127 & 0.5 & 0.57 & & \\
\hline Time $\mathrm{x}$ Dropout & 1.1 & 0.8 & 514 & 1.3 & 0.18 & & \\
\hline
\end{tabular}

Table 3

Fit statistics for 1-6 class latent class growth mixture models.

\begin{tabular}{lllllll} 
n. classes & Log-likelihood & AIC & BIC & SABIC & entropy & $\begin{array}{l}\text { Posterior } \\
\text { probabilities above } \\
90 \% \text { in each class }\end{array}$ \\
\hline 1 & & & & & & \\
2 & -2514.88 & 5043 & 5063 & 5041 & - & - \\
3 & -2495.13 & 5012 & 5043 & 5008 & 0.87 & $77 \%$ \\
4 & -2478.54 & 4987 & 5029 & 4982 & 0.89 & $71 \%$ \\
5 & -2471.56 & 4981 & 5035 & 4975 & 0.93 & $86 \%$ \\
6 & -2453.17 & 4952 & 5018 & 4945 & 0.88 & $72 \%$ \\
& -2444.60 & 4943 & 5020 & 4935 & 0.89 & $79 \%$ \\
\hline
\end{tabular}

adherence to treatment, with a special emphasis, besides psychopharmacotherapy, on the regular attendance to psycho-educational and motivational sessions, cognitive-behavioral psychotherapy, individual family psycho-education and support, and therapeutic group activities (Cocchi et al., 2008; Meneghelli et al., 2010). Nevertheless, at Regional level, despite $72 \%$ of FEP patients receive a good multi-professional coverage, only one-sixth of them are involved in social and leisure activity, and activity devoted to family members are delivered to a minority of them and just $16 \%$ show adherence to the treatment regime 90 days after the start (Lora et al., 2016). Poor adherence to psychopharmacotherapy during the first years after diagnosis influences an enhanced risk of hospital admission in FEP patients who are serviced
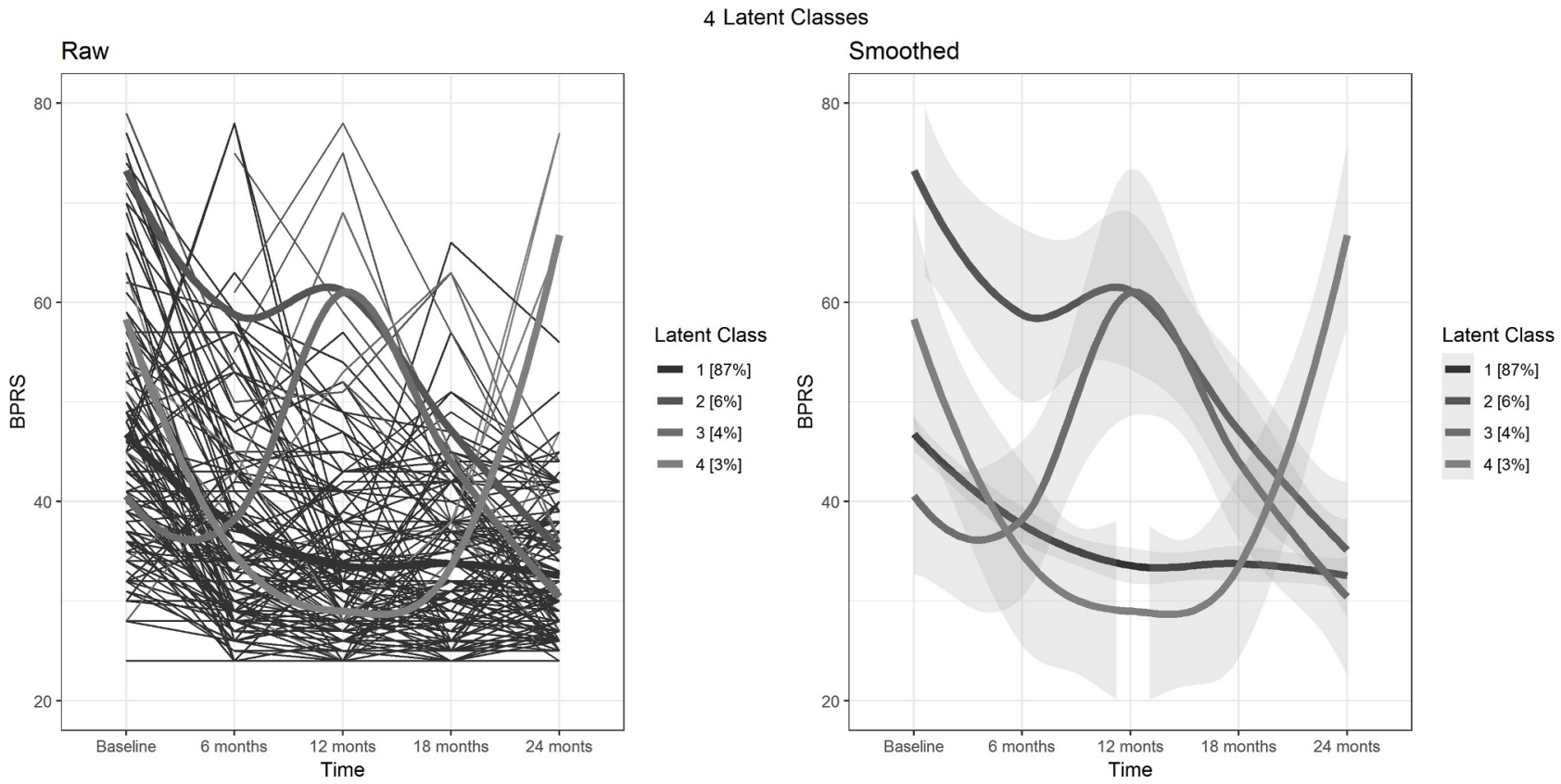

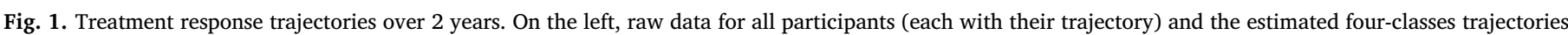

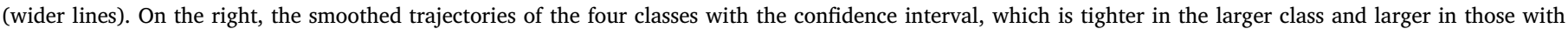
limited sample size. . 
Table 4

Baseline clinical variables across the 4 latent classes.

\begin{tabular}{|c|c|c|c|c|c|}
\hline & Class 1 & Class 2 & Class 3 & Class 4 & McFadden $R^{2}$ \\
\hline & $N=112$ & $N=8$ & $N=5$ & $N=4$ & \\
\hline Gender & & & & & $1.3 \%$ \\
\hline Boys & $93(83 \%)$ & $6(75 \%)$ & $3(60 \%)$ & $3(75 \%)$ & \\
\hline Girls & $19(17 \%)$ & $2(25 \%)$ & $2(40 \%)$ & $1(25 \%)$ & \\
\hline OR $(95 \% \mathrm{CI})$ & 1 & $1.6(0.3-8.7)$ & $3.2(0.5-20.8)$ & $1.6(0.1-16.5)$ & \\
\hline Age (years old) & & & & & $0.3 \%$ \\
\hline 16 to 20 years old & $45(40 \%)$ & $4(50 \%)$ & $2(40 \%)$ & $2(50 \%)$ & \\
\hline 21 years old or older & $67(60 \%)$ & $4(50 \%)$ & $3(60 \%)$ & $2(50 \%)$ & \\
\hline OR $(95 \% \mathrm{CI})$ & 1 & $0.7(0.1-2.8)$ & $1.0(0.1-6.3)$ & $0.7(0.1-4.9)$ & \\
\hline DUP (days) & & & & & $1.1 \%$ \\
\hline Less than 90 days & $39(41 \%)$ & $4(50 \%)$ & $1(20 \%)$ & $1(33 \%)$ & \\
\hline 3 months or more & $56(59 \%)$ & $4(50 \%)$ & $4(80 \%)$ & $2(67 \%)$ & \\
\hline OR $(95 \% \mathrm{CI})$ & 1 & $0.7(0.1-2.9)$ & $2.8(0.3-25.9)$ & $1.4(0.1-15.9)$ & \\
\hline Past admissions for psychiatic reasons & & & & & $5.9 \%$ \\
\hline Yes & $58(52 \%)$ & $5(62 \%)$ & $5(100 \%)$ & $1(25 \%)$ & \\
\hline No & $54(48 \%)$ & $3(38 \%)$ & $0(0 \%)$ & $3(75 \%)$ & \\
\hline OR $(95 \% \mathrm{CI})$ & 1 & $0.6(0.1-2.8)$ & $0(0-0)$ & $3.2(0.3-31.9)$ & \\
\hline History of recreational substance use & & & & & $4.9 \%$ \\
\hline Yes & $24(23 \%)$ & $4(50 \%)$ & $0(0 \%)$ & $2(50 \%)$ & \\
\hline No & $79(77 \%)$ & $4(50 \%)$ & $5(100 \%)$ & $2(50 \%)$ & \\
\hline OR $(95 \% \mathrm{CI})$ & 1 & $0.3(0.1-1.3)$ & $0(0-0)$ & $0.3(0.1-2.3)$ & \\
\hline \multicolumn{6}{|l|}{ Yes } \\
\hline No & $66(66 \%)$ & $5(62 \%)$ & $4(80 \%)$ & $1(33 \%)$ & \\
\hline \multirow[t]{2}{*}{ OR $(95 \% \mathrm{CI})$} & $34(34 \%)$ & $3(38 \%)$ & $1(20 \%)$ & $2(67 \%)$ & \\
\hline & 1 & $1.1(0.2-5.1)$ & $0.5(0.1-4.5)$ & $3.9(0.3-44.3)$ & \\
\hline Decline in premorbid functioning & & & & & $4.5 \%$ \\
\hline Yes & $82(81 \%)$ & $7(87 \%)$ & $2(40 \%)$ & $4(100 \%)$ & \\
\hline No & $19(19 \%)$ & $1(13 \%)$ & $3(60 \%)$ & $0(0 \%)$ & \\
\hline OR $(95 \% \mathrm{CI})$ & 1 & $0.6(0.1-5.3)$ & $6.4(1.0-41.5)$ & $0(0-0)$ & \\
\hline Dropout of treatment after 2 years & & & & & $2.4 \%$ \\
\hline Yes & $33(30 \%)$ & $1(12 \%)$ & $3(60 \%)$ & $1(25 \%)$ & \\
\hline No & $79(70 \%)$ & $7(88 \%)$ & $2(40 \%)$ & $3(75 \%)$ & \\
\hline OR $(95 \% \mathrm{CI})$ & 1 & $2.9(0.3-24.7)$ & $0.3(0.1-1.7)$ & $1.2(0.1-12.5)$ & \\
\hline
\end{tabular}

Latent Class 1 was used as a reference term.

within the Lombardy mental health system of care; these patients rarely display proper use of the community service, in terms of regular attendance for receiving psychotherapy, psychoeducational activities, social supports, and multidisciplinary care (Corrao et al., 2015). Thus, even in the absence of a control group of patients receiving treatmentas-usual, it is reasonable to assume that the improvement observed in the sample is comparable to the superior improvement observed in past studies carried out in early intervention services, especially on positive symptoms (Correll et al., 2018).

However, the improvement was not thoroughly and homogeneous. The LCGA has identified four classes in the treatment response trajectories of the sample, two of them with progressive improvement and two with some worsening over time. No potential predictor of outcome among those that were examined was specifically related to one of these classes, but the limited sample size might have prevented statistical estimation. Nevertheless, those patients incurring in a worsening of their status should be closely evaluated to identify factors that are related to the worsening, including poor compliance to therapy, substance use or the onset of a medical condition impacting on mental status.

\subsection{Strengths and limitations}

The use of state of the art statistics was the main strength of this study. Some limitations have to be acknowledged, too. The sample size was too limited to detect specific associations of the longitudinal classes with some of the predictors of outcome that were investigated in the study. Moreover, the assessment was executed at 6-month intervals, and this might have prevented some finer grounded definition of the trajectories. For some of the predictors, we had only binary data (yes or not), and this might have limited our chance of identifying relevant relationships. Another limitation is the lack of a control group. Indeed, it was not possible to agree with the psychiatric services operating in neighbor areas the application of an assessment detailed and repeated as the one that it is implemented in the Programma2000, thus no data on treatment-as-usual could be collected for comparison.

\section{Conclusions}

The study indicates that patients treated within an early intervention service are likely to undergo substantial improvement of their psychopathology. However, some of these patients may incur a worsening of their psychopathology during treatment and they need close reevaluation.

Antonio Preti, MD, is scientific advisor and consultant to Programma2000.

Mauro Percudani, MD, since July 2017 is the chair of the Dipartimento di Salute Mentale e delle Dipendenze dell'ASST Grande Ospedale Metropolitano Niguarda, Milan, in which the Programma2000 group was settled and operates its activities.

Programma2000 was funded by a grant of the Lombardy Regional Health Authority (Italy).

\section{Contributors}

AM and AC had the idea and organized the study.

AM, MM, and AP contributed by collecting the data and organizing the database for analysis.

AM, AC, MM, SB, and EM contributed to the enrollment, the diagnosis and clinical ascertainment of the patients' sample.

AP undertook the statistical analyses.

$\mathrm{AP}, \mathrm{AM}, \mathrm{SB}$, and EM managed the literature search and contributed 
to the interpretations of the findings.

$\mathrm{AP}$ and AM wrote the initial draft.

MP and SB contributed to the interpretation and discussion of the findings and revised the initial draft into a more general framework.

MP and AM were the guarantors of the study. They had full responsibility for the work and the conduct of the study; they had access to the data and controlled the decision to publish.

All authors contributed to the writing of the first draft and to the final manuscript, which they all approved for submission.

\section{Declaration of Competing Interest}

To the best of their knowledge, all authors declare that they have no conflicts of interest concerning the findings reported in this study.

\section{Acknowledgements}

The Programma2000 group includes: Professor Angelo Cocchi, MD (team leader, $\uparrow$ 2015); Anna Meneghelli, PsyD (clinical and scientific coordinator); Andrea Alpi, PsyD; Laura Bislenghi, PsyD, Giovanni Patelli, PsyD; Federico Galvan, MA (educator); Alessia Pisano, PsyD; Chiara Acerbi PsyD; Stefano Romano` MD (psychiatrist); Daniele von Morghen, MD (psychiatrist); Lara Malvini, MD (psychiatrist); Emiliano Monzani MD (psychiatrist), head of the service until 2019; Simona Barbera, MD (psychiatrist), head of the service since 2019. The team also includes a very active group of psychologists in training.

\section{Supplementary materials}

Supplementary material associated with this article can be found, in the online version, at doi:10.1016/j.psychres.2020.113200.

\section{References}

Akaike, H., 1987. Factor analysis and AIC. Psychometrika 52, 317-332.

Andruff, H., Carraro, N., Thompson, A., Gaudreau, P., Louvet, B., 2009. Latent class growth modelling: a tutorial. Tutor. Quant. Methods. Psychol. 5, 11-24.

Awad, A.G., Voruganti, L.N., 2008. The burden of schizophrenia on caregivers: a review. Pharmacoeconomics 26 (2), 149-162.

Barton, K., 2018. MuMIn: multi-model inference. R package version 1.42.1. http://CRAN. R-project.org/package $=$ MuMIn.

Bennett, M.E., Bradshaw, K.R., Catalano, L.T., 2017. Treatment of substance use disorders in schizophrenia. Am. J. Drug Alcohol. Abuse. 43, 377-390. https://doi.org/10. $1080 / 00952990.2016 .1200592$.

Birchwood, M., 2000. Early intervention and sustaining the management of vulnerability. Aust. N.Z. J. Psychiatry. 34 (Suppl), S181-S184.

Bowtell, M., Ratheesh, A., McGorry, P., Killackey, E., O'Donoghue, B., 2018. Clinical and demographic predictors of continuing remission or relapse following discontinuation of antipsychotic medication after a first episode of psychosis. A systematic review. Schizophr. Res. 197, 9-18. https://doi.org/10.1016/j.schres.2017.11.010.

Cascio, M.T., Cella, M., Preti, A., Meneghelli, A., Cocchi, A., 2012. Gender and duration of untreated psychosis: a systematic review and meta-analysis. Early Interv. Psychiatry. 6, 115-127. https://doi.org/10.1111/j.1751-7893.2012.00351.x.

Charland, L.C., 2015. Esquirol, Jean-Étienne (1772-1840). In: Cautin, R.L., Lilienfeld, S.O. (Eds.), The Encyclopedia of Clinical Psychology, https://doi.org/10.1002/ 9781118625392.wbecp096.

Chau, H.S., Chong, W.S., Wong, J.G.W.S., Hung, G.B.K., Lui, S.S.Y., Chan, S.K.W., Chang, W.C., Hui, C.L.M., Lee, E.H.M., McGorry, P.D., Jones, P.B., Chen, E.Y.H., 2018. Early intervention for incipient insanity: early notions from the 19(th) century English literature. Early Interv. Psychiatry. 12, 708-714. https://doi.org/10.1111/eip.12355.

Cloutier, M., Aigbogun, M.S., Guerin, A., Nitulescu, R., Ramanakumar, A.V., Kamat, S.A., DeLucia, M., Duffy, R., Legacy, S.N., Henderson, C., Francois, C., Wu, E., 2016. The Economic Burden of Schizophrenia in the United States in 2013. J. Clin. Psychiatry. 77, 764-771. https://doi.org/10.4088/JCP.15m10278.

Cocchi, A., Meneghelli, A., Preti, A, 2008 "Programma 2000": celebrating ten years of activity of an Italian pilot program on early intervention in psychosis. Aust. N.Z. J. Psychiatry. 42, 1003-1012.

Corrao, G., Soranna, D., Merlino, L., Monzani, E., Viganò, C., Lora, A., 2015. Do patterns of mental healthcare predict treatment failure in young people with schizophrenia? Evidence from an Italian population-based cohort study. BMJ Open 5, e007140. https://doi.org/10.1136/bmjopen-2014-007140.

Correll, C.U., Galling, B., Pawar, A., Krivko, A., Bonetto, C., Ruggeri, M., Craig, T.J., Nordentoft, M., Srihari, V.H., Guloksuz, S., Hui, C.L.M., Chen, E.Y.H., Valencia, M., Juarez, F., Robinson, D.G., Schooler, N.R., Brunette, M.F., Mueser, K.T., Rosenheck, R.A., Marcy, P., Addington, J., Estroff, S.E., Robinson, J., Penn, D., Severe, J.B., Kane,
J.M., 2018. Comparison of Early Intervention Services vs Treatment as Usual for Early-Phase Psychosis: a Systematic Review, Meta-analysis, and Meta-regression. JAMA Psychiatry 75, 555-565. https://doi.org/10.1001/jamapsychiatry.2018.0623.

Emsley, R., Chiliza, B., Schoeman, R., 2008. Predictors of long-term outcome in schizophrenia. Curr. Opin. Psychiatry 21, 173-177. https://doi.org/10.1097/YCO 0b013e3282f33f76.

Esquirol, J.E.D., 1845. Mental Maladies; A Treatise On Insanity [E. K. Hunt, Trans.]. Lea and Blanchard, Philadelphia.

Häfner, H., Riecher-Rossler, A., Hambrecht, M., 1992. IRAOS: an instrument for the assessment of onset and early course of schizophrenia. Schizophr. Res. 6, 209-223.

Harding, C.M., Brooks, G.W., Ashikaga, T., Strauss, J.S., Breier, A., 1987. The Vermont longitudinal study of persons with severe mental illness, II: long-term outcome of subjects who retrospectively met DSM-III criteria for schizophrenia. Am. J. Psychiatry. 144, 727-735.

Harrison, G., Hopper, K., Craig, T., Laska, E., Siegel, C., Wanderling, J., Dube, K.C., Ganev, K., Giel, R., an der Heiden, W., Holmberg, S.K., Janca, A., Lee, P.W., León, C.A., Malhotra, S., Marsella, A.J., Nakane, Y., Sartorius, N., Shen, Y., Skoda, C., Thara, R., Tsirkin, S.J., Varma, V.K., Walsh, D., Wiersma, D., 2001. Recovery from psychotic illness: a 15- and 25-year international follow-up study. Br. J. Psychiatry. 178, 506-517.

Horton, L.E., Tarbox, S.I., Olino, T.M., Haas, G.L., 2015. Trajectories of premorbid childhood and adolescent functioning in schizophrenia-spectrum psychoses: a firstepisode study. Psychiatry Res 227, 339-346. https://doi.org/10.1016/j.psychres. 2015.02.013.

Immonen, J., Jääskeläinen, E., Korpela, H., Miettunen, J., 2017. Age at onset and the outcomes of schizophrenia: a systematic review and meta-analysis. Early Interv. Psychiatry. 11, 453-460. https://doi.org/10.1111/eip.12412.

Jin, H., Mosweu, I., 2017. The Societal Cost of Schizophrenia: a Systematic Review. Pharmacoeconomics 35, 25-42. https://doi.org/10.1007/s40273-016-0444-6.

Jung, T., Wickrama, K.A.S., 2008. An introduction to latent class growth analysis and growth mixture modeling. Soc. Personal. Psychol. Compass. 2, 302-317.

Käkelä, J., Marttila, R., Keskinen, E., Veijola, J., Isohanni, M., Koivumaa-Honkanen, H., Haapea, M., Jääskeläinen, E., Miettunen, J., 2017. Association between family history of psychiatric disorders and long-term outcome in schizophrenia - The Northern Finland Birth Cohort 1966 study. Psychiatry Res. 249, 16-22. https://doi.org/10. 1016/j.psychres.2016.12.040.

Käkelä, J., Panula, J., Oinas, E., Hirvonen, N., Jääskeläinen, E., Miettunen, J., 2014. Family history of psychosis and social, occupational and global outcome in schizophrenia: a meta-analysis. Acta Psychiatr. Scand. 130, 269-278. https://doi.org/10. 1111/acps.12317.

Kerfoot, K.E., Rosenheck, R.A., Petrakis, I.L., Swartz, M.S., Keefe, R.S., McEvoy, J.P., Stroup, T.S., Investigators., C.A.T.I.E., 2011. Substance use and schizophrenia: adverse correlates in the CATIE study sample. Schizophr. Res. 132, 177-182. https:// doi.org/10.1016/j.schres.2011.07.032.

Kong, F., Chen, Y.F., 2016. Testing treatment effect in schizophrenia clinical trials with heavy patient dropout using latent class growth mixture models. Pharm. Stat. 15, 349-361. https://doi.org/10.1002/pst.1750.

Koo, T.K., Li, M.Y., 2016. A Guideline of Selecting and Reporting Intraclass Correlation Coefficients for Reliability Research. J. Chiropr. Med. 15, 155-163. https://doi.org/ 10.1016/j.jcm.2016.02.012.

Lally, J., Ajnakina, O., Stubbs, B., Cullinane, M., Murphy, K.C., Gaughran, F., Murray, R.M., 2017. Remission and recovery from first-episode psychosis in adults: systematic review and meta-analysis of long-term outcome studies. Br. J. Psychiatry. 211, 350-358. https://doi.org/10.1192/bjp.bp.117.201475.

Laursen, T.M., Nordentoft, M., Mortensen, P.B., 2014. Excess early mortality in schizophrenia. Annu. Rev. Clin. Psychol. 10, 425-448. https://doi.org/10.1146/annurevclinpsy-032813-153657.

Leucht, S., 2014. Measurements of Response, Remission, and Recovery in Schizophrenia and Examples for Their Clinical Application. J. Clin. Psychiatry. 75 (Suppl 1), 8-14. https://doi.org/10.4088/JCP.13049su1c.02.

Levine, S.Z., Rabinowitz, J., Case, M., Ascher-Svanum, H., 2010. Treatment response trajectories and their antecedents in recent-onset psychosis: a 2-year prospective study. J. Clin. Psychopharmacol. 30, 446-449. https://doi.org/10.1097/JCP. 0b013e3181e68e80.

Levine, S.Z., Rabinowitz, J., 2010. Trajectories and antecedents of treatment response over time in early-episode psychosis. Schizophr. Bull. 36, 624-632. https://doi.org/ 10.1093/schbul/sbn120.

Long, J.S., 1997. Regression Models For Categorical and Limited Dependent Variables Sage Publications, Thousand Oaks.

Lora, A., Barbato, A., Cerati, G., Erlicher, A., Percudani, M., 2012. The mental health system in Lombardy, Italy: access to services and patterns of care. Soc. Psychiatry Psychiatr. Epidemiol. 47, 447-454. https://doi.org/10.1007/s00127-011-0352-1.

Lora, A., Monzani, E., Ibrahim, B., Soranna, D., Corrao, G., 2016. Routine quality care assessment of schizophrenic disorders using information systems. Int. J. Qual. Health Care. 28, 728-733. https://doi.org/10.1093/intqhc/mzw096.

McGorry, P.D., 2015. Early intervention in psychosis: obvious, effective, overdue. J. Nerv. Ment. Dis. 203, 310-318. https://doi.org/10.1097/NMD.0000000000000284.

Meneghelli, A., Cocchi, A., Preti, A., 2010. "Programma2000": a multi-modal pilot program on early intervention in psychosis underway in Italy since 1999. Early Interv. Psychiatry. 4, 97-103.

Nakagawa, S., Johnson, P.C.D., Schielzeth, H., 2017. The coefficient of determination R2 and intra-class correlation coefficient from generalized linear mixed-effects models revisited and expanded. J. R. Soc. Interface. 14 (20170213), 1-11.

Overall, J.E., Gorham, D.E., 1962. The brief psychiatric rating scale. Psychol. Rep 10, 799-812.

Parabiaghi, A., Confalonieri, L., Magnani, N., Lora, A., Butteri, E., Prato, K., Vaggi, M., 
Percudani, M., 2019. Integrated Programs for Early Recognition of Severe Mental Disorders: recommendations From an Italian Multicenter Project. Front. Psychiatry. 10, 844. https://doi.org/10.3389/fpsyt.2019.00844.

Penttilä, M., Jääskeläinen, E., Hirvonen, N., Isohanni, M., Miettunen, J., 2014. Duration of untreated psychosis as predictor of long-term outcome in schizophrenia: systematic review and meta-analysis. Br. J. Psychiatry. 205, 88-94. https://doi.org/10.1192/ bjp.bp.113.127753.

Pinheiro, J., Bates, D., DebRoy, S., Sarkar, D., Core Team., R., 2016. nlme: linear and Nonlinear Mixed Effects Models. R package version 3, 1-128. http://CRAN.R-project. org $/$ package $=$ nlme

Proust-Lima, C., Philipps, V., Liquet, B., 2017. Estimation of extended mixed models using latent classes and latent processes: the R package lcmm. J. Stat. Soft. 78, 1-56.

R Core Team., 2018. R: A language and Environment For Statistical Computing. R Foundation for Statistical Computing, Vienna, Austria URL. http://www.R-project. org/.

Raballo, A., Meneghelli, A., Cocchi, A., Sisti, D., Rocchi, M.B., Alpi, A., Cascio, M.T, Preti, A., Maurer, K., Häfner, H., 2014. Shades of vulnerability: latent structures of clinical caseness in prodromal and early phases of schizophrenia. Eur. Arch. Psychiatry Clin. Neurosci. 264, 155-169. https://doi.org/10.1007/s00406-013-0421-4.

Rabinowitz, J., Davidov, O., 2008. The association of dropout and outcome in trials of antipsychotic medication and its implications for dealing with missing data. Schizophr. Bull. 34, 286-291. https://doi.org/10.1093/schbul/sbm161.

Ramaswamy, V., DeSarbo, W.S., Reibstein, D.J., Robinson, W.T., 1993. An empirical pooling approach for estimating marketing mix elasticities with PIMS data. Market Sci 12, 103-124.

Riecher-Rössler, A., Butler, S., Kulkarni, J., 2018. Sex and gender differences in schizophrenic psychoses-a critical review. Arch. Womens Ment. Health 21, 627-648. https://doi.org/10.1007/s00737-018-0847-9.

Roncone, R., Ventura, J., Impallomeni, M., Falloon, I.R., Morosini, P.L., Chiaravalle, E.,
Casacchia, M., 1999. Reliability of an Italian standardized and expanded Brief Psychiatric Rating Scale (BPRS 4.0) in raters with high vs. low clinical experience. Acta Psychiatr. Scand. 100, 229-236.

Santesteban-Echarri, O., Paino, M., Rice, S., González-Blanch, C., McGorry, P., Gleeson, J., Alvarez-Jimenez, M., 2017. Predictors of functional recovery in first-episode psychosis: a systematic review and meta-analysis of longitudinal studies. Clin. Psychol. Rev. 58, 59-75. https://doi.org/10.1016/j.cpr.2017.09.007.

Schwarz, G., 1978. Estimating the dimension of a model. Ann. Stat. 6, 461-464 1978.

Sclove, S.L., 1987. Application of model-selection criteria to some problems in multivariate analysis. Psychometrika 52, 333-343.

Ventura, J., Green, M.F., Shaner, A., Liberman, R.P., 1993. Training and quality assurance with the Brief Psychiatric Rating Scale: "The drift busters. Int. J. Methods Psychiatr. Res. 3, 221-244.

Volavka, J., Vevera, J., 2018. Very long-term outcome of schizophrenia. Int. J. Clin. Pract. 72, e13094. https://doi.org/10.1111/ijcp.13094.

Watson, P., Zhang, J.P., Rizvi, A., Tamaiev, J., Birnbaum, M.L., Kane, J., 2018. A metaanalysis of factors associated with quality of life in first episode psychosis. Schizophr. Res. 202, 26-36. https://doi.org/10.1016/j.schres.2018.07.013.

Winslow, F., 1858. The legal doctrine of responsibility in cases of insanity, connected with alleged criminal acts. J. Psychol. Med. Ment. Pathol. 11, 214-246.

Winslow, F., 1860. On Obscure Diseases of the brain, and disorders of the mind: Their Incipient symptoms, pathology, diagnosis, treatment, and Prophylaxis. Blanchard \& Lea, Philadelphia.

World Health Organization., 1992. Tenth Revision of the International Classification of Diseases and Related Health Problems (ICD-10). WHO Press, Geneve.

World Medical Association., 2013. World Medical Association Declaration of Helsinki: ethical principles for medical research involving human subjects. JAMA 310 2191-2194. https://doi.org/10.1001/jama.2013.281053. 